Murmurations:

Journal of

Transformative

Systemic

Practice

\title{
Chaos, Fear, Conspiracy and Uncertainty
}

\author{
Freda McEwen
}

\section{Volume 3}

Issue 1

Autumn 2020

\section{Keywords:}

autism, family,

Covid-19,

coronavirus

Citation Link

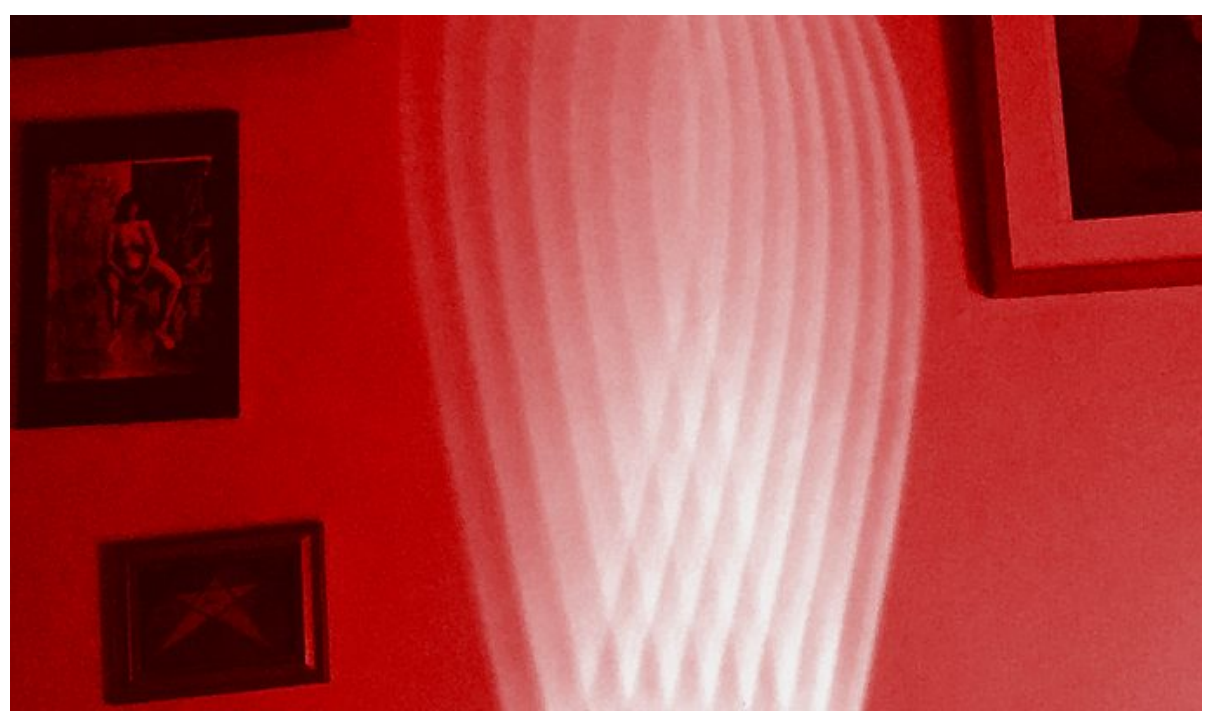

Chaos, fear, conspiracy and uncertainty

The overwhelming chill of the unknown

The fear of being attacked by the unknown

The evidence overtook common sense

The speculation, secrets, suspicions

were more evidential than the evidence

Impossible to reason with reason as there is no reason

People held at ransom

Imprisoned by safety

and forced to keep safe

face to face overtaken by social media

The unconscious more real than the unconscious

Dreams more tangible than life experience

Air became sparse

Life became scarce

Healthy and unhealthy left

Gasping for breath forgetting they ever breathed

The air infused with toxins

and fear of death

and dying alone 
Graveyards enriching its territory with untimely residents Worrisome as family reunion became a war zone

Battling forgotten issues

Exhumed by the present climate

A remake of settled squabbles due to idleness

Intolerance, fist, preying on and being preyed on

Love becomes questionable as families struggle to contain

One another due to fear of contamination

The hostility, the guile, the wickedness

Of the pandemic cut across all

Race, culture, age, gender, class, statue, rank

And left none untouched

Some wishing they could buy the terror

and transfer it to the vulnerable and poor

Pride eloping and ego fleeing as the elites

And the wealthy are forced to gasp for last breath

Night became day and day night

Time crawling and moving slower than the heart beat

Everyone is fearful

Everyone is tearful

Everyone is confused

Shattered by the nightmare of who

and what is next

This is World war

provoked by the unknown

casualties taken unaware

not opportune to run for safety

or build bomb shelters

It seems inevitable

There is no choice

Here I am battling the psycho terror autism

As it tries to wreck my peace and takeover my space

My son could not comprehend the chaos

To him it is normal and fascinating

Watching people pace up and down

Looking terrified and bemused

Washing hands is the best part

Since he is obsessed with running the tap

There is not much difference except

Movement is limited and more people are at home

Watching people wearing mask is like a circus

$\mathrm{He}$ is fascinated by it

He sees it as a costume, mere dress up

The social distance he loves

As he hates people invading his space 
The wait is the problem

It builds his anxiety and trigger

Counting every grain of sound and getting

Burnt out and fully spent

Meanwhile my daughter

Got fully acquainted with the kitchen

A place only mum goes

Rolling out one dish after the other

Taking out tape to ensure no inches are added in her waist line

Playing dress up and getting ready to go nowhere

Frustrating but a lesson to learn

Away from friends and indoors with family

This is stifling as her brother's screaming takes a toll on me

Being in the house was too much to ask of him

Engaging my daughter with conversation was boring to her

My focus is on the present pandemic

She just wants to sweep it under the carpet

She wants to pretend it is an imagination

She entertains herself as much as she can

At least she always has a smile

Especially when she speaks to her friends

I am no longer interested in social media

Which, could have interested her

I am entrapped by motherhood

Trying to contain and curtail their emotions

This erupts all over the place

Thrown uncannily at my face

Without reservations or concern

I am glad for my spirituality and that is my inner strength

It keeps me hopeful and helpful

So I got hooked in it

I got disinterested in the media

It became disruptive, thought provoking and annoying

As it shatters my hope when I am in the process of eloping with it

I stopped listening

I stopped watching

I just started listening to the rhythm of my heartbeat

And, the sequence of my pupil dilation

It is horrifying but yet thrilling

Sending goose pimples down my spine

I could hear the pin drop in the universe

Hoping to reverse the deeds

The silence and pain no one can comprehend

I cuddle up to the unseen, inner companion and comforter 


\author{
Knowing he will grant me audience \\ Even If everything fails \\ And nothing stands \\ As I get sandwiched into an unending lullaby \\ The rhythm rhymes with my inner turmoil \\ The trauma awakening my unconscious fear \\ and sending my conscious confidence \\ to an unending search for answers.
}

\title{
Citation
}

McEwen, Freda (2020) Chaos, Fear, Conspiracy and Uncertainty. Murmurations: Journal of Transformative Systemic Practice, 3, 1, 1-4. https://doi.org/10.28963/3.1.2 